P66 SARCOPENIA IN COPD: PREVALENCE, CLINICAL CORRELATES AND RESPONSE TO PULMONARY REHABILITATION

${ }^{1}$ SE Jones, ${ }^{2} \mathrm{M}$ Maddocks, 'SSC Kon, ${ }^{1} \mathrm{JL}$ Canavan, ${ }^{1} \mathrm{CM}$ Nolan, ${ }^{3} \mathrm{AL}$ Clark, ${ }^{1} \mathrm{Ml}$ Polkey, ${ }^{1}$ WD-C Man. ${ }^{1}$ NIHR Respiratory Biomedical Research Unit, Royal Brompton and Harefield NHS Foundation Trust and Imperial College, Harefield, UK; ${ }^{2}$ King's College London, Cicely Saunders Institute, London, UK; ${ }^{3}$ Harefield Pulmonary Rehabilitation Unit, Royal Brompton and Harefield NHS Foundation Trust, Harefield, UK

\subsection{6/thoraxjnl-2014-206260.207}

Background Sarcopenia is age-related loss of skeletal muscle mass leading to increased risk of physical disability, poor health status and death. Although sarcopenia is primarily an age-related condition, it is recognised that there are multiple contributing factors, notably from immobility and the effects of chronic disease. International consensus working groups have defined sarcopenia as a loss of muscle mass and reduced muscle strength or function. Although skeletal muscle dysfunction is well recognised in chronic obstructive pulmonary disease (COPD), the prevalence of sarcopenia (defined using international consensus guidelines) and the impact of sarcopenia upon functional capacity and health related quality of life (HRQoL) have not been previously described in patients with COPD. Furthermore, it is not known whether sarcopenia affects the response to pulmonary rehabilitation (PR).

Methods Sarcopenia was determined using the European Working Group on Sarcopenia in Older People (EWGSOP) algorithm in 622 outpatients with stable COPD. Other measurements included incremental shuttle walk (ISW), five-repetition sit-to-stand (5STS), quadriceps maximum voluntary contraction (QMVC) and HRQoL (St George's Respiratory Disease (SGRQ) and COPD Assessment Test (CAT)). Response to PR was determined in 43 patients with sarcopenia and compared with a control group identified using propensity score matching. Baseline characteristics and change pre- to post-PR were compared between groups.

Results Prevalence of sarcopenia was 14.5\% (16.1\% men and $12.3 \%$ women; $p=0.20$ ), which increased with advancing quartiles of age and GOLD spirometric stage. Patients with sarcopenia were older, had worse air flow obstruction, reduced QMVC, exercise capacity and HRQoL (Table 1). Both sarcopenic patients and controls showed significant improvements in exercise capacity, functional performance, QMVC and HRQoL with PR, with no between group differences. Following PR, 12/43 (28\%) patients no longer met EWGSOP criteria for sarcopenia.

Abstract P66 Table 1 Baseline clinical characteristics of sarcopenic and non-sarcopenic COPD patients expressed as mean (SD) and median $\left(25^{\text {th }}\right.$ and $75^{\text {th }}$ centiles)

\begin{tabular}{llll}
\hline & $\begin{array}{l}\text { Non-sarcopenic } \\
(\mathbf{n}=532)\end{array}$ & $\begin{array}{l}\text { Sarcopenic } \\
(\mathbf{n}=90)\end{array}$ & p-value \\
\hline Age (years) & $70(10)$ & $73(8)$ & $\mathbf{0 . 0 0 3}$ \\
Sex (M:F) & $297: 235$ & $57: 33$ & 0.112 \\
MRC & $3(1)$ & $4(1)$ & 0.028 \\
FEV1\% predicted & $44.00(30.00,59.00)$ & $37.00(26.75,50.00)$ & $\mathbf{0 . 0 0 3}$ \\
Weight (kg) & $78.48(19.47)$ & $58.58(13.69)$ & $<\mathbf{0 . 0 0 0 1}$ \\
BMI (kg/m²) & $28.62(6.13)$ & $21.43(3.99)$ & $<0.0001$ \\
CAT & $21(8)$ & $24(9)$ & 0.001 \\
SGRQ Total & $52.09(17.02)$ & $57.11(17.47)$ & $\mathbf{0 . 0 1 1}$ \\
ISW (m) & $222(148)$ & $157(118)$ & $<0.0001$ \\
4MGS (m/s) & $0.90(0.24)$ & $0.77(0.22)$ & $<\mathbf{0 . 0 0 0 1}$ \\
5STS (secs) & $14.05(11.42,18.96)$ & $19.55(12.92,60)$ & $<\mathbf{0 . 0 0 0 1}$ \\
Handgrip (kg) & $27.61(10.04)$ & $21.46(7.26)$ & $<\mathbf{0 . 0 0 0 1}$ \\
Peak QMVC $(\mathrm{kg})$ & $24.99(9.37)$ & $18.26(6.94)$ & $<0.0001$ \\
\hline
\end{tabular}

Conclusion There is a high prevalence of sarcopenia in patients with COPD which is associated with reduced exercise capacity and HRQoL. Sarcopenia does not impact upon response to pulmonary rehabilitation in COPD.

\section{P67 LARYNGEAL NARROWING IN CHRONIC OBSTRUCTIVE PULMONARY DISEASE (COPD): A MECHANISM FOR GENERATING INTRINSIC PEEP?}

${ }^{1} \mathrm{M}$ Baz, ${ }^{2} \mathrm{GS}$ Haji, ${ }^{2} \mathrm{~A}$ Menzies-Gow, ${ }^{2} \mathrm{RJ}$ Tanner, ${ }^{2}$ NS Hopkinson, ${ }^{2} \mathrm{Ml}$ Polkey, ${ }^{2} \mathrm{JH}$ Hull. ${ }^{1}$ Universidad de La Republica, Montevideo, Uruguay; ${ }^{2}$ NIHR Respiratory Biomedical Research Unit, Royal Brompton and Harefield NHS Foundation Trust and Imperial College, London, UK

\subsection{6/thoraxjnl-2014-206260.208}

Introduction and rationale Patients with COPD often exhibit pursed lip breathing during exercise, a strategy to help overcome a rise in intrinsic PEEP secondary to dynamic hyperinflation. A similar role for laryngeal closure to optimise respiratory mechanics during exertion is postulated.

Objectives Assessment of laryngeal narrowing and its role in exercise intolerance and dynamic hyperinflation in COPD.

Methods and Measurements: We studied 30 age and sex matched subjects ( $\mathrm{n}=11$ healthy, $\mathrm{n}=8$ mild to moderate COPD, $\mathrm{n}=11$ severe COPD). Baseline physiological characteristics and clinical status were assessed prior to an incremental maximal cardiopulmonary exercise test with continuous laryngoscopy. Laryngeal narrowing was calculated at the glottic and supra-glottic aperture at rest and peak exercise.

Results Expiratory laryngeal narrowing was pronounced in patients with COPD at rest and peak exercise and related to $\mathrm{FEV}_{1}(\mathrm{r}=-0.53$, $\mathrm{p}<0.05$ and $\mathrm{r}=-0.70, \mathrm{p}<0.001$ respectively). Glottic narrowing at peak exercise correlated with inspiratory duty cycle time (Ti/Ttot) (Figure), this was not seen at rest $(\mathrm{r}=-0.79, \mathrm{P}<0.0001$ and $\mathrm{r}=-$ $0.07, \mathrm{p}=0.77$ respectively). Laryngeal closure at peak exercise inversely correlated with peak oxygen uptake $(r=-0.68, p<0.01)$.

Conclusion Dynamic laryngeal closure during expiration is prevalent in patients with COPD and is related to disease severity, respiratory duty cycle and exercise capacity.

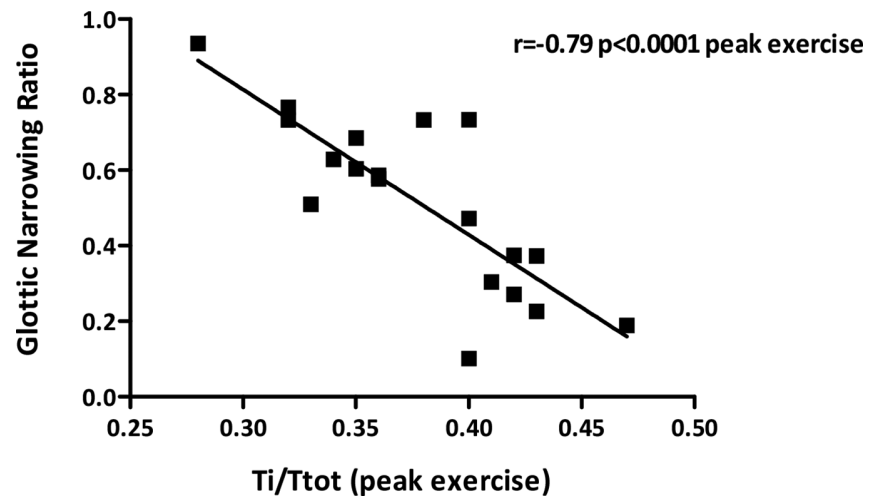

Abstract P67 Figure 1

\section{P68 TIME-COURSE OF HUMAN RHINOVIRUS INFECTION AND UPPER RESPIRATORY TRACT SYMPTOMS DURING COPD EXACERBATIONS}

SN George, SE Brill, JP Allinson, R Singh, B Kowlessar, RJ Sapsford, GC Donaldson, JA Wedzicha. National Heart and Lung Institute, Imperial College, London, UK

10.1136/thoraxjnl-2014-206260.209 